\title{
Successful Non-Surgical Intervention for Massive Gastric Distention due to Malignant Duodenal Obstruction
}

\author{
Yazeed A. Khojah, MD \\ Diplomate, American Board of Family Medicine \\ Fellow, Palliative Medicine, University of Miami/Jackson Memorial Hospital \\ Miami, FL., USA \\ Department of Family and Community Medicine \\ King Abdulaziz University, Jeddah, Saudi Arabia
}

\section{Correspondence}

Dr. Yazeed A. Khojah

P.O. Box 80215, Jeddah 21589, Saudi Arabia

e.M: ykhojah@kau.edu.sa

Submission: 02 Nov. 2016

Accepted: $\quad 11$ Nov. 2016

\section{Citation}

Khojah YA. Successful non-surgical intervention for massive gastric distention due to malignant duodenal obstruction. JKAU Med Sci 2017; 24

(1): 49-52. DOI: 10.4197/Med. 24.1.6

\begin{abstract}
Gastroduodenal obstruction in pancreatic cancer is common and sometimes challenging to treat. A 35-year-old man with advanced pancreatic cancer receiving palliative chemotherapy presented with worsening abdominal pain, nausea, vomiting and increased abdominal girth. Computed tomography scan of the abdomen revealed significant malignant duodenal obstruction with massive gastric distention. A non-surgical endoscopic intervention with placement of a self-expanding metallic duodenal stent successfully relieved the obstruction and ameliorated symptoms. The patient was able to resume eating normally again. Gastrointestinal stenting is a less invasive and effective alternative to surgical gastrojejunostomy. Stent placement as a palliative treatment for patients with malignant duodenal obstruction and massive gastric distention may be considered as a first line treatment for such patients.
\end{abstract}

\section{Keywords}

Massive gastric distention; Malignant duodenal obstruction; Duodenal stent and surgical gastrojejunostomy

\section{Introduction}

W ith advances in cancer treatment and improvements in patient survival, malignant duodenal obstruction in pancreatic cancer is becoming more common; literature reports an incidence of up to $38 \%$ when cancer is advanced ${ }^{[1]}$. There is no evidence in the literature to determine whether surgical or nonsurgical management is better for palliating malignant obstruction with massive gastric distension. This is a report of successful treatment of malignant duodenal obstruction and symptomatic improvement by endoscopic, non-surgical stent placement for massive gastric distention.

\section{Case Report}

This was a 35-year-old man with advanced pancreatic cancer on palliative chemotherapy who presented with worsening abdominal pain, nausea, vomiting and increased abdominal girth. Computed tomography (CT) abdomen scan showed significant duodenal obstruction with massive gastric distention (Figure 1). In consultation with surgical oncology who verbally 


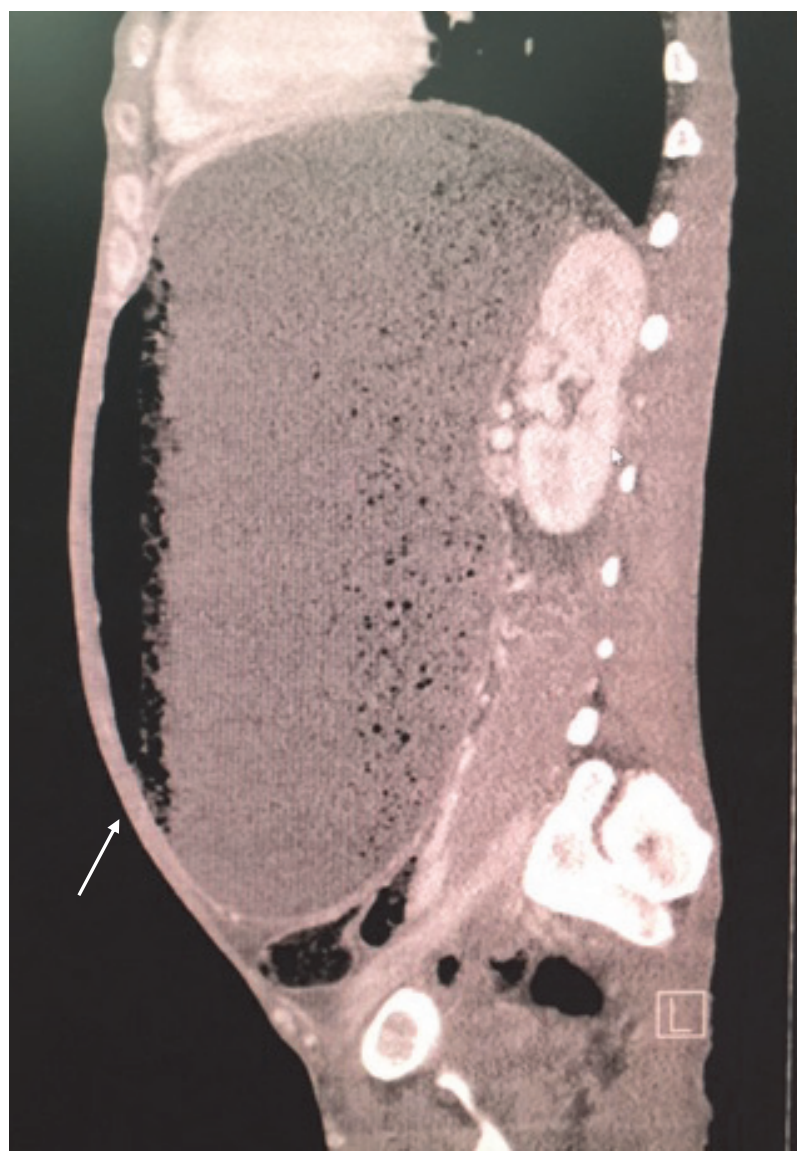

Figure 1. Massive gastric distention (arrow) with air fluid level.

estimated the gastric volume at 20 liters, a decision was made to proceed with stent placement before a surgical alternative was offered.

A self-expanding metallic stent was successfully placed by endoscopy under fluoroscopic guidance in the severely, extrinsically stenotic second portion of the duodenum. The patient was able to tolerate a liquid diet on post-procedure day 2 . His diet was advanced incrementally and by day 7 he was able to tolerate a regular diet and eat normally; his presenting symptoms and gastric distension improved concurrently. Additionally, he required less pain medications, his functional activities and breathing improved and overall quality of life improved significantly.

Follow up CT scan 20 days later showed significant improvement with only mild gastric distention (Figure 2). The patient did not need any further surgical intervention. He tolerated oral intake until his death 11 weeks later.

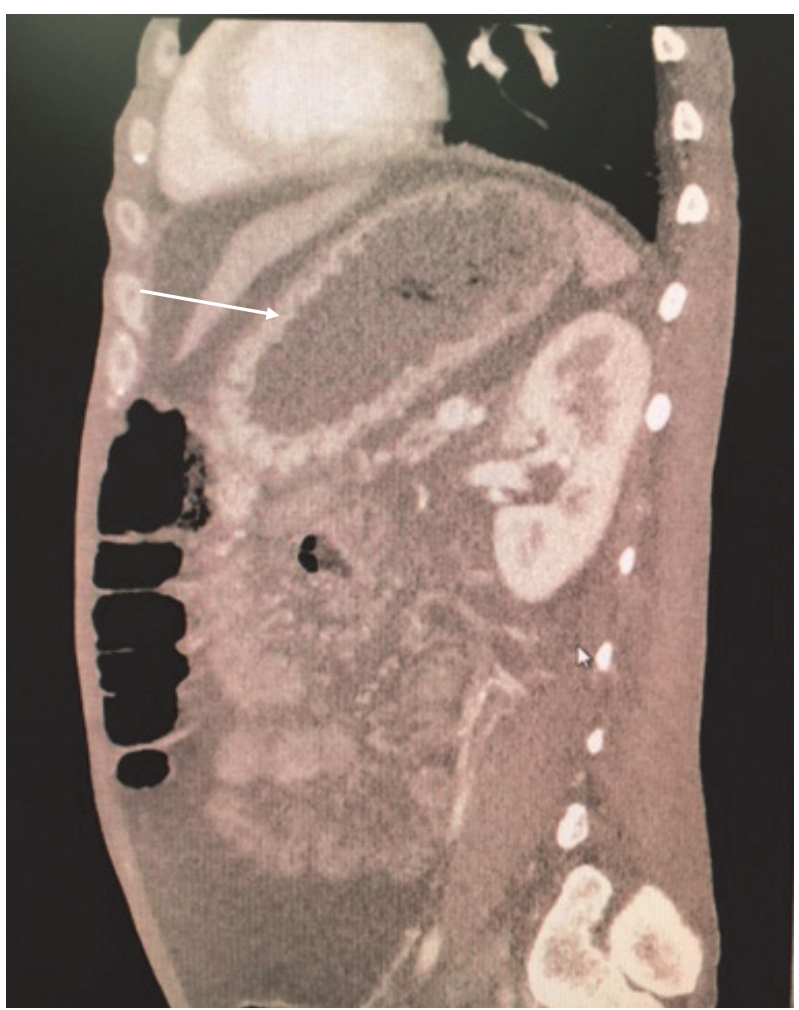

Figure 2. Dramatic reduction (arrow) in gastric distention.

\section{Discussion}

Gastroduodenal obstruction in pancreatic cancer is common.

Historically, palliative surgical gastrojejunostomy has been the gold standard therapy but it is associated with high morbidity and mortality rates ${ }^{[2]}$ and a high incidence of gastric delayed emptying which impacts the patient's quality of life ${ }^{[3]}$. Palliative gastrointestinal stenting is a less invasive alternative and an effective intervention in treating malignant gastric outlet obstruction ${ }^{[4]}$. It is associated with faster return of oral intake, shorter hospital stay, fewer immediate and short term complications and possibly a longer survival rate ${ }^{[3,5]}$. Multiple case series have reported that palliative stenting is an effective alternative to gastrojejunostomy; randomized controlled trials, however, have reported mixed results ${ }^{[4,6,7]}$. Additionally, there is no data available on which intervention is best in the subset of patients with massive gastric distension. 
The successful outcome in this case raises the possibility that stenting, even in patients with massive gastric distention secondary to pancreatic cancer, is a viable alternative to surgery for sustained palliative relief of gastric outlet obstruction and ameliorating symptoms.

\section{Conclusion}

In a patient with single defined obstruction, palliative duodenal stenting offers a non-surgical treatment alternative for massive gastric distention secondary to duodenal obstruction in pancreatic cancer that may eliminate the need for future surgical intervention.

\section{Conflict of Interest}

The author has no conflict of interest.

\section{Disclosure}

The author did not receive any type of commercial support either in forms of compensation or financial for this study. The author has no financial interest in any of the products or devices, or drugs mentioned in this article.

\section{Ethical Approval}

\section{Obtained.}

\section{References}

[1] Shah A, Fehmi A, Savides TJ. Increased rates of duodenal obstruction in pancreatic cancer patients receiving modern medical management. Dig Dis Sci 2014; 59(9): 2294-2298.

[2] Nagaraja V, Eslick GD, Cox MR. Endoscopic stenting versus operative gastrojejunostomy for malignant gastric outlet obstruction-a systematic review and meta-analysis of randomized and non-randomized trials. J Gastrointest Oncol 2014; 5(2): 92-98.

[3] Chandrasegaram MD, Eslick GD, Mansfield CO, Liem $\mathrm{H}$, Richardson M, Ahmed S, Cox MR. Endoscopic stenting versus operative gastrojejunostomy for malignant gastric outlet obstruction. Surg Endosc 2012; 26(2): 323-329.

[4] Adler DG, Baron TH. Endoscopic palliation of malignant gastric outlet obstruction using self-expanding metal stents: experience in 36 patients. Am J Gastroenterol 2002; 97(1): 72-78

[5] Wong YT, Brams DM, Munson L, Sanders L, Heiss F, Chase M, Birkett DH. Gastric outlet obstruction secondary to pancreatic cancer: surgical vs endoscopic palliation. Surg Endosc 2002; 16(2): 310-312.
[6] Mehta S, Hindmarsh A, Cheong E, Cockburn J, Saada J, Tighe R, Lewis MP, Rhodes M. Prospective randomized trial of laparoscopic gastrojejunostomy versus duodenal stenting for malignant gastric outflow obstruction. Surg Endosc 2006; 20(2): 239-242.

[7] Jeurnink SM, Steyerberg EW, van Hooft JE, van Eijck $\mathrm{CH}$, Schwartz MP, Vleggaar FP, Kuipers EJ, Siersema PD; Dutch SUSTENT Study Group. Surgical gastrojejunostomy or endoscopic stent placement for the palliation of malignant gastric outlet obstruction (SUSTENT study): a multicenter randomized trial. Gastrointest Endosc 2010; 71(3): 490-499. 

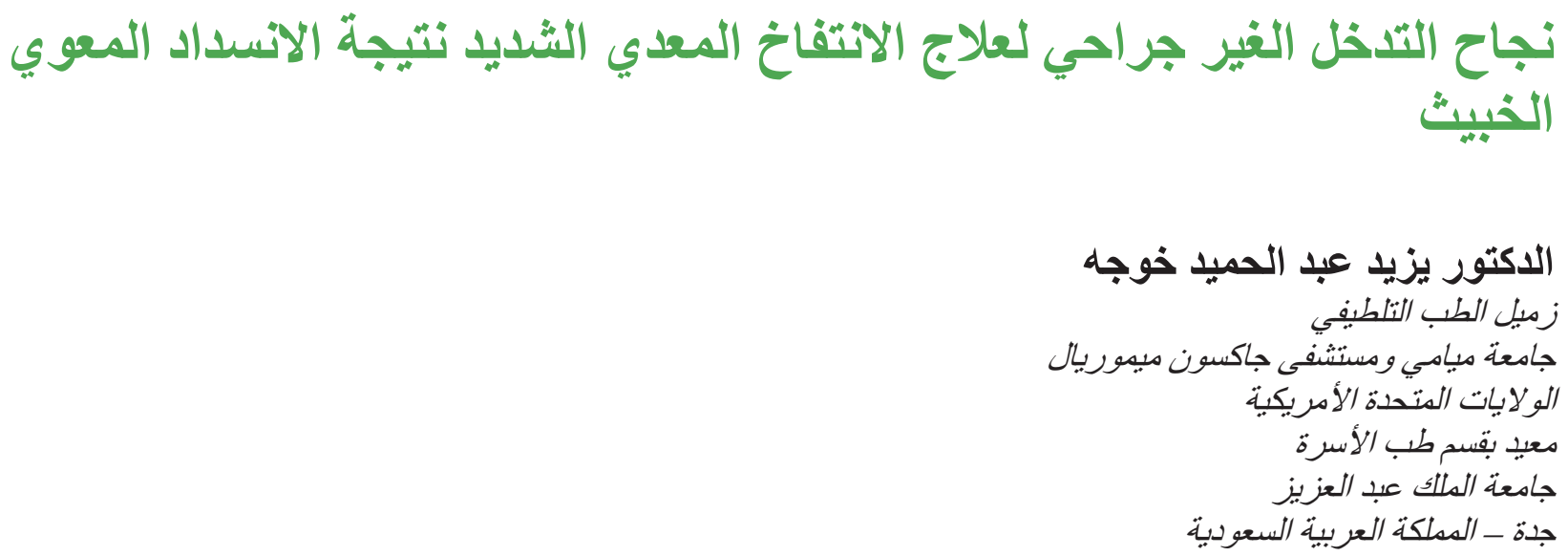

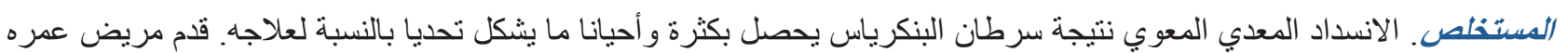

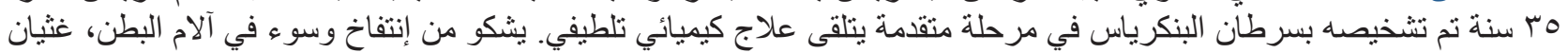

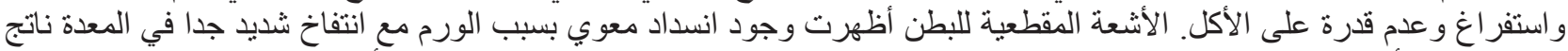

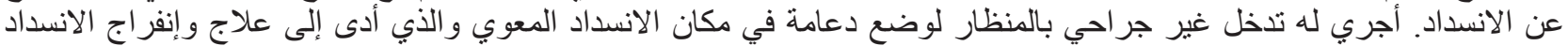

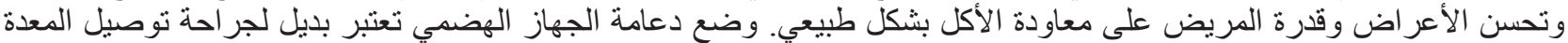
بالأمعاء الدقيقة. وجود هذا التدخل الطبي. التلطيفي والغير جر احي قد يستعمل كخيار أولي في حالات انسداد و انتفاخ المعدة الثنديد نتيجة الأور ام الخبيثة. 